\title{
Training Medical Students as COVID-19 first contact responders: Integrating Telemedicine and Medical Education during a Health System Crisis in Sri Lanka
}

\author{
Karunathilake, I.M. ${ }^{1}$, Edirisinghe, E.A.S.T. ${ }^{2}$, Hettiarachchi, D. ${ }^{1}$, Perera, B.J.C. ${ }^{3}$, Hamdani, A. ${ }^{4}$, \\ Kohombange, C. ${ }^{4}$, Herath, $T^{5}{ }^{5}$, Amarasiri, M. ${ }^{1}$, Randenikumara, $S .{ }^{3}$, Mudiyanse, ${ }^{5}{ }^{5}$, \\ Senanayake, D. ${ }^{1}$, Ihsan, F.R. ${ }^{1}$, Guruge, $K^{3}{ }^{3}$, Ragunathan, M.K. ${ }^{3}$
}

\section{Introduction}

Any healthcare system can face a crisis during an epidemic where the need for manpower exceeds the capacity. Medical students have the potential to be an asset in such situations, where the health sector, patients and the medical students themselves would benefit. Medical students have contributed to patient care during the Spanish flu outbreak in 1918 and the polio epidemic in Denmark in 1952 (Starr, 1976). Medical students' involvement in service provision during the current pandemic addressed the potential shortage of frontline workforce and contributed to reduction of the overall burden on clinical teams (Starr, 1976, West, 2005, Miller et al., 2020). This paper discusses an innovative approach to integrate telemedicine and medical education during the COVID-19 pandemic response in Sri Lanka.

Sri Lanka's COVID-19 situation saw a rapid rise in case numbers from July 2021. During the peak of the surge, the number of daily reported test- positive patients exceeded 5000 with 220

${ }^{1}$ Faculty of Medicine, University of Colombo, Sri Lanka

${ }^{2}$ Faculty of Medical Sciences, University of Sri Jayewardenepura, Sri Lanka

${ }^{3}$ Sri Lanka Medical Association

${ }^{4}$ Ministry of Health, Sri Lanka

${ }^{5}$ Faculty of Medicine, University of Peradeniya, Sri Lanka

Corresponding author: Prof. Indika Karunathilake Indika@medarc.cmb.ac.lk cases per million population and a ranking of 50 in the world-wide affected country list $(\mathrm{MOH}$, 2021). The number of deaths too were rapidly increasing. The numbers of healthcare workers available for optimal functioning of the system too declined with a significant proportion acquiring the infection and the remaining workforce having to contend with physical and mental exhaustion. Therefore, the healthcare system of the country was reaching a tipping point, with an unprecedented rise in demand for the rapidly dwindling resources (Jensen et al., 2020). It was necessary to prevent overburdening the already fraught hospitals as well as staff $(\mathrm{MOH}, 2021$; Karunathilake et al., 2021; Karunathilake, 2020; Karunathilake et al., 2020).

One option to respond to the situation was to establish a virtual triaging system for the identification and evacuation of those who needed hospitalization and to facilitate home management for mildly symptomatic and asymptomatic patients.

\section{The intervention}

The Doc Call 247 Service under the Sri Lanka Medical Association (SLMA) has been in operation since 2020 to provide telephone based medical advice for COVID-19 directly to patients and catered to their needs. As the number implies, it is a twenty-four hour, seven days a week service, made available in all three national languages, Sinhala, Tamil and English, used in Sri Lanka. Doc Call 247 service consists entirely of volunteers ranging from

DOI: http://doi.org/10.4038/seajme.v15i2.378

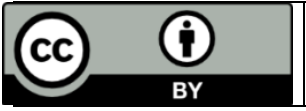

C SEAJME. This is an Open Access article distributed under the terms of the Creative Commons Attribution License (http://creativecommons.org/licenses/by/4.0/), which permits unrestricted use, distribution, and reproduction in any medium, provided the original author and source are credited 
specialists to medical students. Since the expected number of calls was high, the service decided to recruit and train medical students as first contact responders. At the time of initiation, medical education of students in Sri Lanka was limited to online lectures and clinical training was on halt for most academic batches. Thus, recruiting medical students to the system created the opportunity to train them in healthcare provision without actually exposing them to the ongoing pandemic.

Volunteers were invited through social media groups. The volunteers, including doctors and medical students, were trained separately via initial online training programmes. Training needs were identified according to the diverse levels of knowledge and experience of volunteers. A range of competencies, including clinical reasoning, patient management, communication skills, teamwork, health education and handling difficult situations had to be inculcated. This included training on how to assess a patient and get all essential information within the system allocated time limit of 10 minutes.

The content of the training workshop was identified based on expert opinions on COVID19 clinical pathophysiology and epidemiology. Identified resources and training material were compiled as a guidebook. Social media such as WhatsApp, YouTube and Facebook were utilized for disseminating and sharing knowledge. Recommended reading was made available and education of the entire group adopted a non-activist approach - participants knew where to find information and relied on "knowledge stored in others" to take up the challenge of handling possibly critical lifethreatening situations. Added to that, regular training sessions and discussions were arranged to keep pace with new developments in the pandemic with regard to new variants, vaccines and local epidemiological data as well on queries raised by the first contact responders and callers.

The volunteers (doctors and medical students) were provided with predetermined set of questions based on COVID-19 red flag signs to help with assessment (Figure 1).
- What was the date of symptom onset?

- What was the date of test positivity?

- What are the symptoms? Difficulty in breathing, fever not responding to paracetamol, chest pain or any other sinister symptoms

- Existing comorbid conditions - diabetes, hypertension, ischaemic heart disease, chronic kidney disease, chronic lung diseases etc.

- Other complicating factors such as extremes of age, pregnancy, obesity, smoking and availability of family/social support

Based on the initial assessment, it was decided whether the patient was in need of urgent hospitalization or not (Figure 2).

On-the-job learning was an integral component of this activity. Students were able to get specialist opinion on patient management whenever required through a dedicated social media platform. Several WhatsApp groups were formed with all volunteers including specialists, senior doctors, junior doctors, interns and medical students. The volunteers could send information about their assessment and patient's health status and the specialists and senior doctors could give further advice with clinical reasoning, which was then relayed to the patient. A tag system was used in order to avoid entries being overlooked, in which medical specialists were assigned to entries in relevance to the specialty. Volunteers would call the patient back and relay further advice and information and keep track when indicated as the communications network was made tollfree by network partners.

\section{The outcome}

An initial group of 300 medical students were recruited and trained. Later the number increased to 600 . The total number of medical doctors available in the system was around 300.This portal ensured that those who required hospitalization were given priority for evacuation. Asymptomatic or mildly symptomatic patients were given necessary advice and were able to recover at home with regular medical advice. 


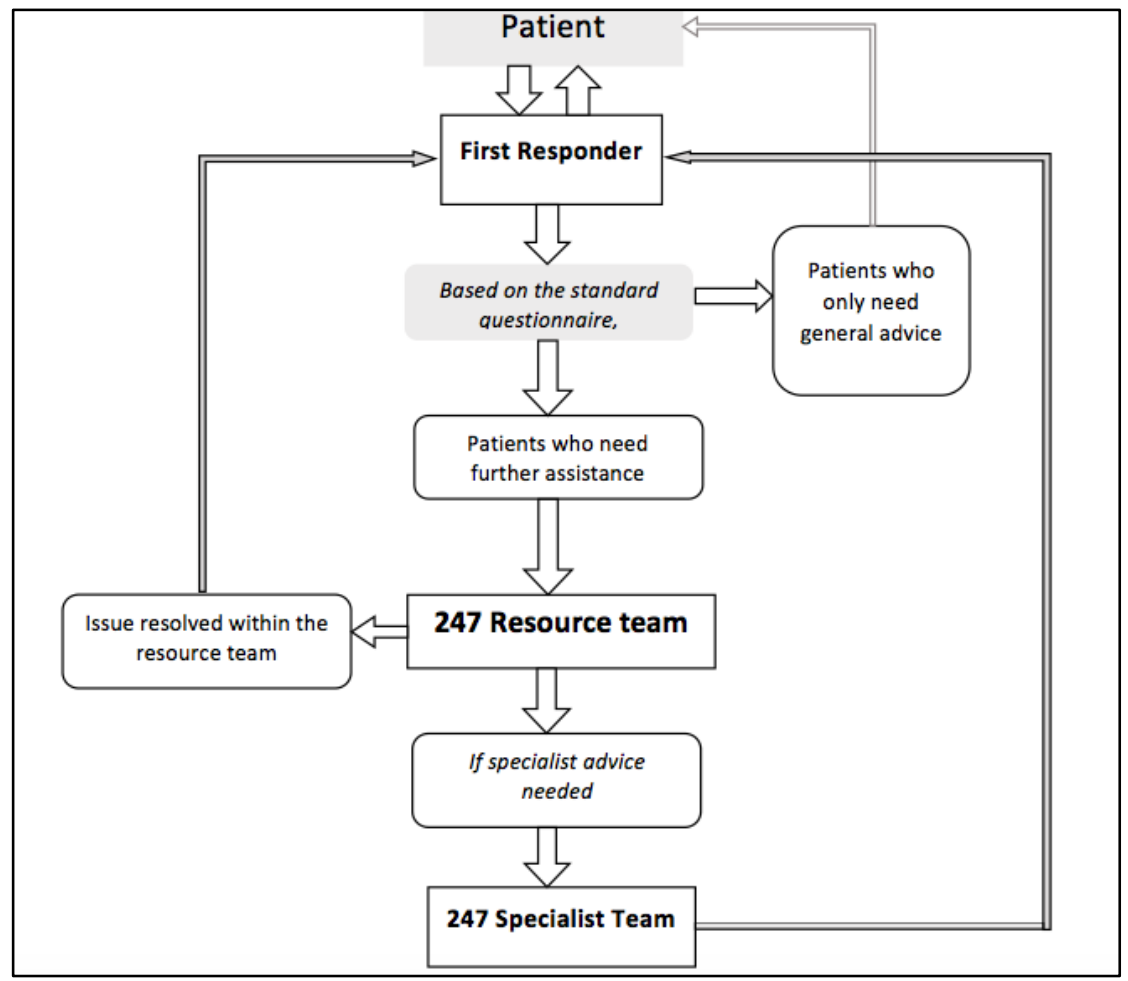

Figure 2: Patient triage flow chart

As at 14th November 2021, Doc Call 247 has attended to over 60,000 patients. Out of the 60,000 calls received on Doc call 247 , only around 1,300 patients needed urgent care and hospitalization. There were no on-admission deaths reported with the 247 service.

The medical student volunteers responded to incoming calls, with the cumulative total being 29,426 calls over a four month period. The range of calls responded to by medical students ranged from 1 to 1,093, with a mean of 68 calls. Feedback from the volunteer medical students was obtained by circulating a Google form in

September 2021. There were 223 responses. Majority of volunteers were from Sri Lankan state medical schools. Most of the medical students who have volunteered with Doc Call 247 were from Universities of Sri Jayewardenepura and Colombo, being $32 \%$ and $28 \%$ respectively. The level of satisfaction regarding their voluntary participation for the Doc Call 247 was assessed using a 10 point Likert Scale in which ten denoted "highly satisfied" and one being "highly dissatisfied". The overall satisfaction of the medical students during the participation was at a higher level with satisfaction scores of 8 and above accounting for $95 \%$ of the responses, and a moderate satisfaction scores between 5-7 comprising $4 \%$ of the responses. Only two participants (1\%) reported a satisfaction level of 4, which was the lowest value among the student responses. Medical students had high satisfaction levels on the administrative support given by the SLMA Doc Call 247 team to solve the students' problems, with 184 students (83\%) reporting being highly satisfied and 35 students $(16 \%)$ out of the 223 students were satisfied. (Figure 3).

On inquiry whether the SLMA Doc Call 247 service disturbed the routine academic work, 202 students $(91 \%)$ responded that it did not affect their academic work and commented that participation helped them to improve their medical knowledge. A minority (4\%, nine students) reported that it disturbed their daily academic work, of which, four students found it to be manageable. 


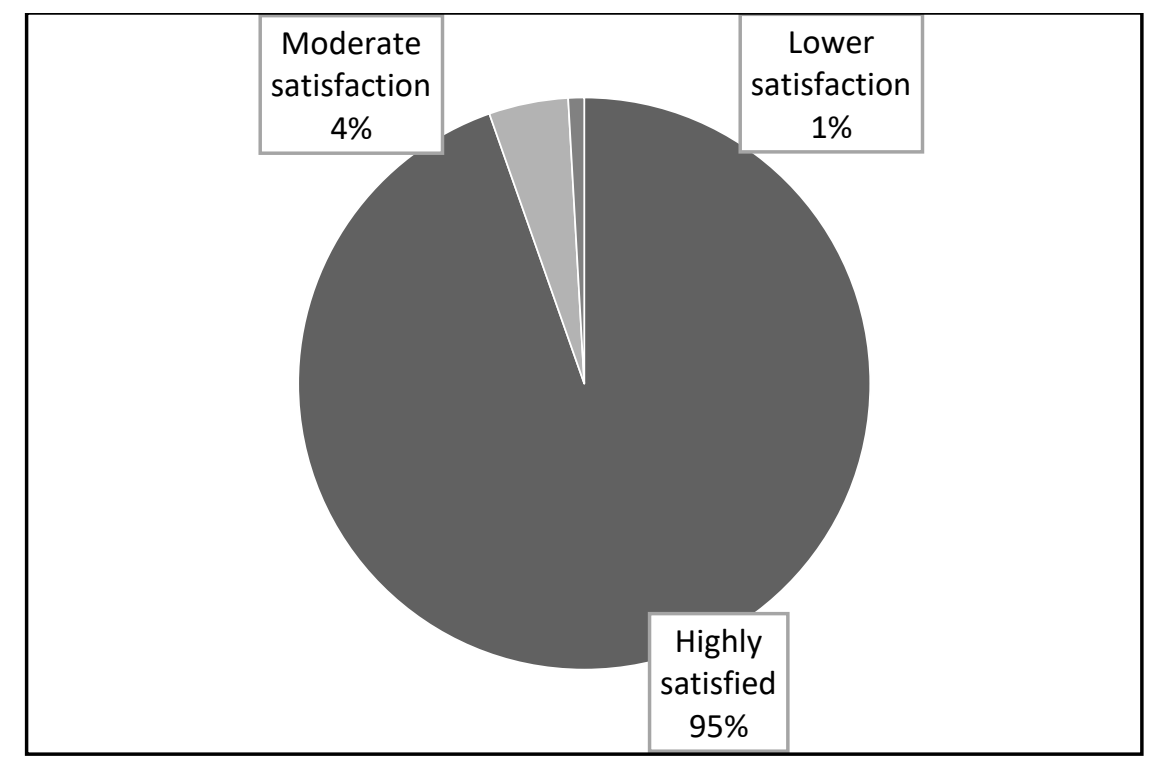

Figure 3: Results of the survey carried out among medical student who volunteered with the 247 hotline with regards to overall satisfaction they had on 247 service

When students were asked whether they would recommend Doc Call 247 service to their colleagues to join and serve, 222 students replied in the affirmative. Most importantly, all 223 students agreed that the Doc Call 247 service helped them to update their existing knowledge on COVID-19.

Students made suggestions for further expansion such as recruitment of more medical officers, and volunteer medical students, promotion of Doc Call 247 via social media and thereby creating public awareness, training and educating volunteers on a regular basis and providing better preparation to the students before getting them enrolled into the team, using all three major languages in order to cater to the caller needs, introducing a mobile app where patients can directly contact the relevant consultant and facilitate follow up, and establishing a simple mechanism in order for the students to keep track of the recorded calls.

Analysis of the students' opinion on whether the Sri Lanka Medical Association (SLMA) should expand the Doc 247 services to a more national level activity, $216(97 \%)$ of students agreed while $7(3 \%)$ of students disagreed. The students who agreed on this aspect further mentioned that this expansion is needed in order to provide medical advice on dengue, cardiovascular related diseases, mild diseases, home accidents, and non-communicable diseases. Promotion of this service to the general public, provision of information on regular clinics and vaccination centers, promotion and guidance on mental health, and prevention of spread of misinformation on COVID-19 were other areas identified for expansion.

Patients who obtained assistance within the first two months from the initiation of 247 hotline were randomly selected using simple random sampling technique in order to assess their feedback about the quality of the service provided. Figure 4 (A, B) illustrates responses of 267 participants to 2 statements. A majority (88\%) agreed that the advice provided by the hotline service was helpful for them during their recovery from the illness. A similar proportion were of the opinion that they received clear advice on managing themselves during the illness. It is thereby evident that an overwhelming majority of patients who obtained assistance from the helpline system were satisfied with the service and benefited from it. 

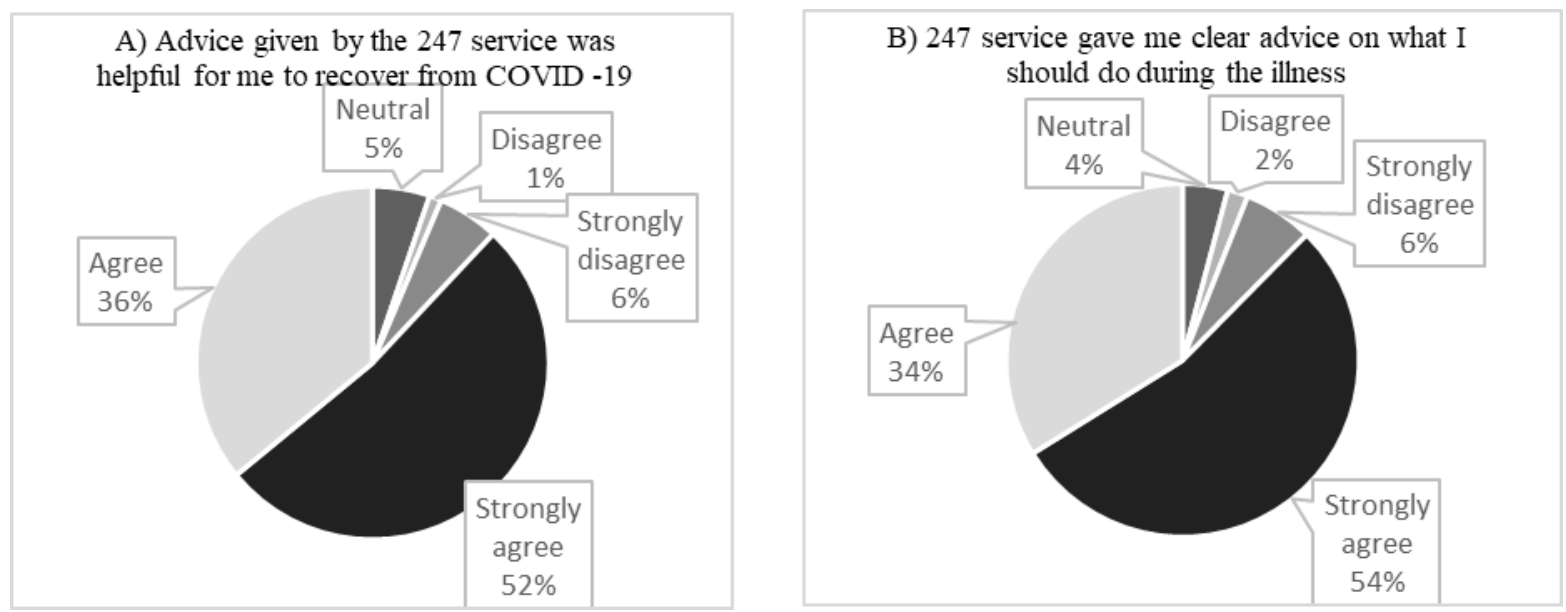

Figure 4: (A) and (B) Results of the survey carried out among patients who obtained assistance

\section{Discussion}

The scope of learning available through the Doc Call 247 service, covers almost all aspects of medicine, from public health to management of emergencies. The system is well structured with an inbuilt referral system. The volunteer medical officers and students obtain the history of the patients/callers, the cases are referred to the relevant specialist within the system if specialist advice is needed. This approach facilitates onthe-job training with supervision by the specialists. Thus, this provided a unique opportunity to introduce telemedicine training into the medical school curriculum, highlighting the need to train future doctors to become competent in using available technologies when providing patient care. It was also an opportune moment to sensitize the students on ethical implications, professionalism, and the practice of safe, evidence-based medicine (Jumreornvong et al., 2020, Bronfenbrenner, 1995).

Several expatriate medical professionals also rendered their services as volunteers to sustain the helpline, transforming this operation to a truly global telemedicine project. They were particularly helpful to cover night time calls and ensure $24 / 7$ service, as it was daytime in many of the countries of residence of the expatriates. Furthermore, it is evident from student feedback that this unique opportunity was an enjoyable learning experience. This opportunity could enable active learning, critical thinking, enhanced problem-solving skills and a change in their approach towards patient care for e.g. a larger proportion of the diagnosis was made from a careful history taking alone which is a useful mindset change for future clinicians, especially in an era where we are heavily dependent on investigations (Hampton et al., 1975, Goldie, 2016, Yang et al., 2020).

The Doc Call 247 volunteer service is a display of connectivism, the learning paradigm of the digital era. Very senior and experienced doctors and a wide range of specialists and junior doctors had no hesitation in sharing advice and information with each other.

Training a diverse group of volunteers to work in a complex system was a major trial. The communication network created in the process of online consultation resulted in an effective, efficient and supportive community of learners. Committed volunteers of all levels of knowledge and experience were ready to devote their time and energy with real altruism to support fellow countrymen. The process was made effective due to the availability of a range of experts in diverse specialties as well as linguistic abilities. The Doc Call 247 service thus facilitated peer to peer learning, which had suffered tremendously when lectures were solely delivered through online platforms due to the pandemic (Hardavella et al., 2017). Additionally, the group enthusiasm 
was boosted by regular appreciative feedback by the leadership and a mutually supportive ecosystem of learners driven by sheer necessity was created by the situation. The process of community engaged learning displayed a bioecological model of learning and high levels of selflessness and volunteerism in action.

\section{Conclusion}

In a time where the world was at a standstill and in-person medical education too was severely curtailed, the Doc Call 247 system could facilitate clinical learning of students to a significant extent. Further, the involvement of expatriate doctors, specialists and medical officers made this system a knowledge-sharing platform. This system is a unique example of integrating medical education with telemedicine during COVID-19. Considering imminent care needs during the present pandemic it has harnessed support from multiple stakeholders, including sectors previously underutilized in the provision of healthcare such as information and communication systems.

In addition to the confirmed benefits to patients and the healthcare system, allowing students to participate in voluntary activities during crisis situations such as COVID-19 reinforces important values, such as altruism, service in times of crisis, and solidarity with the profession. Students are willing and able to contribute during the global challenge and should be given the opportunity to do so.

\section{References}

Bronfenbrenner, U. (1995) Ecological models of human development. In. T. Husen and TN Postlethwaithe [Eds]. International Encyclopedia of Education, Oxford, Pergammon, pp. 1643-1647.

Goldie, JGS (2016) Connectivism: A knowledge learning theory for the digital age? Medical Teacher, 38, pp. 1064-1069.

Hampton, JR., Harrison, M, Mitchell, JR, Prichard, JS \& Seymour, C. (1975) Relative contributions of history-taking, physical examination, and laboratory investigation to diagnosis and management of medical outpatients. British Medical Journal, 2, pp. 486-489.
Hardavella, G, Aamli-Gaagnat, A, Frille, A, Saad, N, Niculescu, A. \& Powell, P. (2017). Top tips to deal with challenging situations: doctor-patient interactions. Breathe, 13, pp. 129-135.

Jensen, T, Holgersen, MG, Jespersen, MS, Blomberg, SN, Folke, F, Lippert, F \& Christensen, HC. (2020). Strategies to handle increased demand in the COVID-19 crisis: a coronavirus EMS support track and a web-based Self-Triage system. Prehospital Emergency Care, 25, pp. 28-38.

Jumreornvong, O, Yang, E, Race, J \& Appel, J. (2020). Telemedicine and medical education in the age of COVID-19. Academic Medicine, 95, 12, pp. 18381843. Doi: 10.1097/ACM.0000000000003711.

Karunathilake, I. 2020. Beyond 2020: Moving Towards New Normal in Medical Education. South-East Asian Journal of Medical Education, 14, 2, p. 1.

Karunathilake, I, Amarasiri, M \& Hamdani, A. (2021). Application Of Statistical Modeling to Interpret a Health System Crisis in Sri Lanka Due To COVID19. Preprints 2021, 2021120455 (doi: 10.20944/preprints202112.0455.v1).

Karunathilake, I, Dissanayake, V, Yasawardena, S, Abegunawardena, A, Raviraj, S, Wijesinghe, P, Anthony, A, Wijesinghe, R, Bowatte, S \& Wickramaratne, N. (2020). The new normal of medical education-challenges and opportunities. South-East Asian Journal of Medical Education, 14, 1, pp. 2-5.

Miller, DG, Pierson, L \& Doernberg, S. (2020). The role of medical students during the COVID-19 pandemic. American College of Physicians. Annals of Internal Medicine, 173, 2, pp.145-146.

MOH 2021. Ministry of Health Sri Lanka COVID-19 Situational Analysis Dashboard. http://wwwhealthgovlk/moh_final/english/public/elfi nder/files/library/Statisticshtml. [Accessed: 13 January 2022]

Starr, I. (1976). Influenza in 1918: recollections of the epidemic in Philadelphia. Annals of Internal Medicine, 85, 4, pp. 516-518.

West, JB. (2005). The physiological challenges of the 1952 Copenhagen poliomyelitis epidemic and a renaissance in clinical respiratory physiology. Journal of Applied Physiology, 99, 2, pp. 424-432.

Yang, Y, Peng, F, Wang, R, Guan, K, Jiang, T, Xu, G, Sun, J and Chang, C, (2020). The deadly coronaviruses: The 2003 SARS pandemic and the 2020 novel coronavirus epidemic in China. Journal of autoimmunity, 109, p.102434. 